\title{
The creative suburb: building and urban designs for suburban innovators
}

\author{
M. Holz \\ Queensland University of Technology, Australia
}

\begin{abstract}
Influential creative industries and creative place thinkers Richard Florida and Charles Landry agree that creativity is necessary for a prospering liveable and, therefore, sustainable city. Following Florida's work, the 'creative class' has become central to what has turned out to be city-centre-centric growth policies. However, until the Queensland University of Technology's Australian Research Council sponsored research into "creative suburbia", few researchers had demonstrated - let alone challenged - the notion that a substantial cohort of creative industries workers might prefer to live and work at home in the suburbs rather than in city centres. The "creative suburb" work builds on the creative suburbia research. In a practice-led and property development industry embedded inquiry, the creative suburb draws on significant primary research with suburban, home-based, creative industries workers, vernacular architecture, and town planning in the Toowoomba region, in the state of Queensland, Australia, as inspiration for a series of new building and urban designs available for innovators operating in new suburban greenfield situations and suburban areas undergoing a refit in Queensland and possibly further afield. This paper focuses on one building design informed by this inquiry, with the intention of its construction as a 'showcasestudy' 'homeworkhouse', suitable for creative industries workers in the Toowoomba region.

Keywords: creativity, creative city, creative suburbia, vernacular architecture, urban design, building design, town planning, creative suburb.
\end{abstract}

\section{Introduction}

The creative suburb is a practice-led, action research project, which emerged from the authors' 27 years of professional practice in the planning, design and delivery of suburban development in south-east Queensland, Australia. The research 
responds to the circumstance that despite attempts by some progressive local governments and housing and property developers to introduce a mix and variety of well-designed housing and land uses, Australian suburbia still comprises homogenous tracts of large detached houses on large lots, home to workers in commercial, retail and industrial areas, often many kilometres away. As in other western countries, this situation is hardly sustainable.

In economic terms alone, the spectre of repossession from failure to meet housing mortgage repayments struck hard during and after the global financial crisis 2008/9 as a result of "sub-prime" (undesirable) lending on repetitively large houses (so-called "McMansions") in the United States. In western nations, where home ownership accounts for a large proportion of residents' wealth, the talk around the dinner and coffee table is no longer about how big one's house is, rather how small one's debt is. The monetary, as well as social and environmental costs of living in the suburbs - including having to drive to and from work, shops and services somewhere else - are now being carefully reconsidered.

The "creative class" (Florida [1,2]) has known of the benefits of living in or close to a major centre in the city for as long as the suburbs have been set on; the search for cheaper living and working conditions, close to cafés, culture and other creative people, is what drove artists and writers of the Beat Generation (such as Allen Ginsberg) to move into disused warehouses in San Francisco during the 1950s. This is what similar creative industries workers (CIWs) continue to do in living and working inner-city locations such as The Valley and West End in Brisbane, Queensland today.

Florida [3], for example, confirmed the "creative class" preference to live and work in funky, diverse, inner-city areas. Landry [4] expanded Florida's [1] original notion into a city-centric policy-orientated toolkit for urban innovators. Evans [5] outlined rationales for cultural and creative industry "quarters", ostensibly in the city. Evans argues that these creative clusters are a key contributor to a knowledgebased (creative) economy.

For CIWs involved in the interlocking and often interdependent fields of art, film, and interactive gaming, or providing business-to-business services in areas such as architecture, advertising and marketing, design, as well as web, multimedia and software development (Higgs et al. [6]), the inner city is an obvious choice. But what if you happen to be an artist or designer (part of the 'super-creative core' identified by Florida [1]) who cannot find an affordable place in the highly sought after city centre, a location attractive to management or legal experts (the 'creative professionals' identified by Florida [1]) who may have driven the price of purchase or renting a place out of reach of even the most commercially successful of the super creative core? What if you happen to be a CIW who does not like the frenetic energy of city centres, what if your work relies on a brief or commission, which can be received and worked on remotely, or what if you prefer a suburban home-based situation to fulfil what may be simply a personal desire for artistic exploration?

The ideal of a more self-contained, self-sufficient and sustainable suburbia spawned this research: to consider the potential for a greater diversity of typically 
smaller and more affordable houses, home-based business and mixed-use centres to contribute to a suburbia in which creative industries workers may be attracted to live and work.

\section{Queensland suburbia}

Furthering the findings of researchers who have determined that home-based creative industries workers work beyond the inner cities (Collis et al. [7], Gibson et al. [8], Flew [9]) and that there is a need to look outside the inner cities to help ensure that the economic and social benefits of creative industries are equitably geographically distributed (Gibson et al. [8]), this research project focused on one of Queensland's most suburbanised regions. The suburbs of Toowoomba and the towns within the Toowoomba Regional Council (TRC) local government area provide the physical spatial context and the TRC planning scheme (scheme) (TRC [10]) provides the statutory context for this research.

The current TRC planning scheme came into effect on 1 July 2012. It is the first scheme to be introduced and gazetted under the Queensland Sustainable Planning Act 2009 (SPA [11]) and includes unprecedented planning provisions designed to facilitate the development of a greater diversity of more affordable housing and home-based business in the region (including the house on top of the shop), rather than impede their development, the latter the case historically in Queensland and in particular in Toowoomba.

The traditional zoning approach in Queensland, evidenced in the old Toowoomba region planning scheme (TRC [10]), separates land uses. In the same way "McMansions" may have a separate room for every use (e.g. dining room, drawing room, media room), so the traditional zoning approach has a zone for every land use (e.g. detached housing, attached housing, retail, commercial, industrial). The economy and vibrancy coming from the dwelling place being close to, connected or coincident with the work place has eroded, and in most instances, eradicated over time by the application of these zoning approaches.

Whilst only a couple examples of these (typically small) houses on tops of shops (mixed-use buildings) have been observed in the Toowoomba region, remnants remain in the towns and suburbs in other locations in south-east Queensland, including “The Old Bakery”, Eumundi on Queensland's Sunshine Coast and in Brisbane, 48 Enoggera Terrace, Red Hill (Figures 1 and 2).

Partly due to draconian planning laws and the general conservatism of the development industry, the majority of new development in the outer suburbs of Toowoomba and the towns in the region have traditionally been large (600 to 800 square metres) lots for large (4 bedroom, two bathroom, plus double lock-up garage) homes (Figure 3); whilst new "infill" development in the inner suburbs and in the small towns and villages throughout the region has been sporadic, mainly as a result of costly, complicated and lengthy development approval processes, but also due to old and, to some extent, new scheme requirements to preserve existing heritage and neighbourhood character buildings in some suburbs of Toowoomba (city) (Figure 4). 


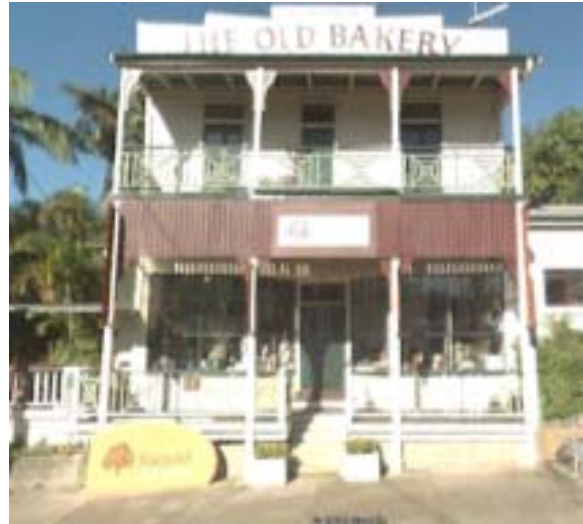

Figure 1: "The Old Bakery" Eumundi, Queensland.

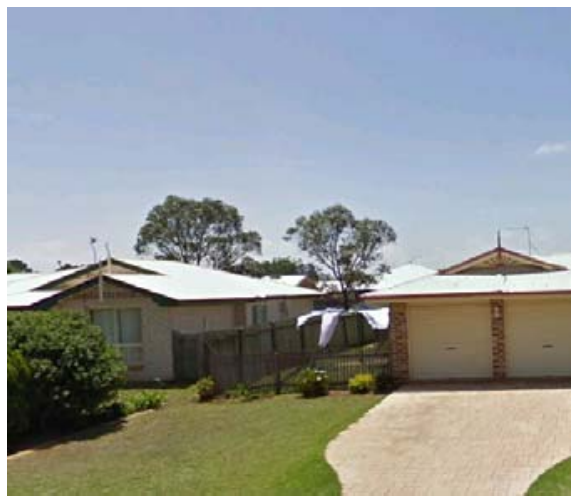

Figure 3: New suburban houses, Toowoomba, Queensland.

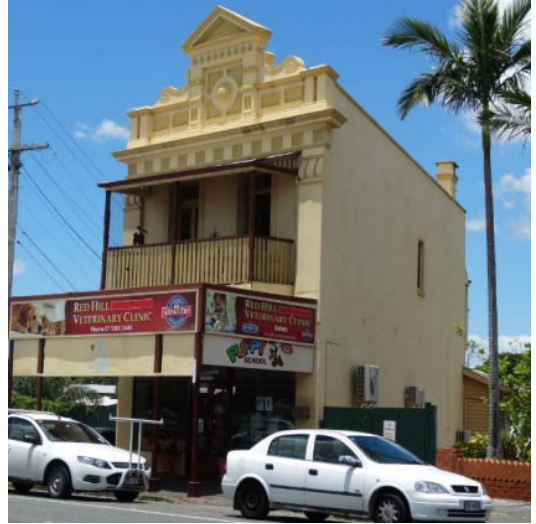

Figure 2: 48 Enoggera Terrace, Red Hill, Brisbane.

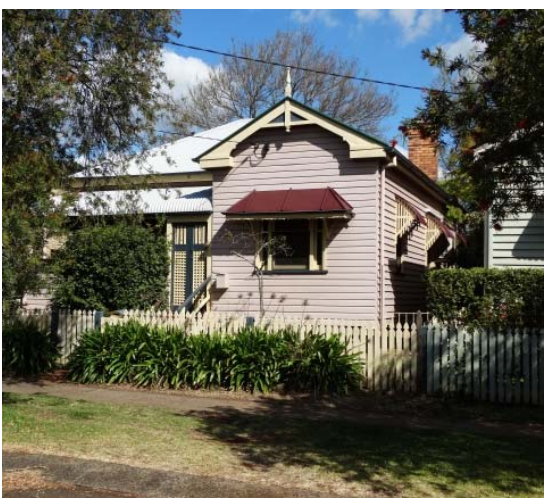

Figure 4: Colonial suburban house, Toowoomba, Queensland.

In contrast to the limitations of the old planning scheme, the new scheme allows smaller houses to be built on lots without any prescribed minimum size, and encourages "home-based business" with no maximum floor area in areas zoned for "residential choice" and "mixed use" development in the majority of inner and outer suburbs of Toowoomba and towns throughout the region (TRC [10]).

The possibility to deliver mixed use in a home-based business setting, without the need to obtain a planning or building permit, is one of the features of the scheme. As a result, some of the best prospects to plan, design and build a new 'homeworkhouse' are to be found in the suburbs in the small towns throughout the Toowoomba region. Indeed, the "small country town" arose in the research as an idea to balance and bridge the city-country dichotomy evident in suburbandwelling CIWs who desire, if not demand, space and serenity for effective creative activity (Collis and Felton [12]). 
The recency of the TRC scheme means that the development industry has not had the opportunity to fully deliver on its promising provisions; built examples for lived experience and/or evaluation are not yet available. It is also highly unlikely that the community and/or customers considering an investment are aware of the live-work and/or home-based business opportunities that may be available under the scheme. New designs and interventions are required to demonstrate these opportunities. A key aim of this research was, therefore, to present ideas and if possible construct one building to demonstrate ideas that may be taken up by the planning, design and development industries and help deliver more mixed-use neighbourhoods and a more creative suburbia, at least in the Toowoomba region.

To make these interventions is a challenge in the Toowoomba region where momentum for large, mono-cultural outer-suburbia prevails, and infill development in inner suburbs needs to accommodate existing character buildings. These challenges, however, proved to be the greatest opportunities.

\section{A creative suburb in Queensland}

A principal task of the creative suburb research was to determine what conditions would suit creative industries workers if they were to be enticed to live and work in the suburbs. Was it in complete contradiction to 1950-70s Heidegger, that the dwelling house and work place may no longer be "here" and "there", but rather, potentially and poetically, coincident, in the suburbs, where typically (paraphrasing Heidegger [13]) "houses" might still be the cheapest, well planned, easy to keep, open to air, light, and sun, but, almost inevitably, are not designed to facilitate home-based business nor creative industries?

The "Soho" (small office home office) is a relatively recent attempt at dwelling and workplace integration; a modern variant of the old shop top house. In a study of Soho's and Soho workers in Australia, Williams et al. [14] reveal a number of positives and negatives of this form of home-based business including: a better demarcation between office and home activities; issues of suburban social isolation with a correspondent need to connect to the local community and physical environment; the need for organised business networking opportunities that can lead to new business opportunities; and concerns about surrounding road and parking infrastructure, which cater to residential needs but not to the needs of collocated businesses.

In addition, as its name implies, the Soho is primarily designed for commercial and possibly, some retail/wholesale activities. Whilst popular in some mixed-use centre developments such as Varsity Lakes on Queensland's Gold Coast, the office-orientation of the Soho does not cater for creative industries workers who may require or prefer a studio or workshop space in which to work.

This research was, therefore, initially concerned with discovering the spatial requirements for home-based business of a full range of CIWs, including those possibly needing larger spaces (e.g. dancers, musicians' performance and recording, visual artists and sculptors) as well as CIWs who may only require a small commercial/office space or a computer/desk in which to carry out their 
home-based business (e.g. CIWs involved in advertising and marketing, architecture and design, software development and creative writing).

Whilst new urbanists such as Katz [15] and Duany et al. [16] have continued their laudable call to end suburban sprawl, the idea of a "creative suburb" had not been fully explored until the Australian Research Council's creative suburbia project. Collis et al. [7] and Flew [9] identified CIWs also choosing to live and work in the outer suburbs. Felton and Collis [17] note that the creative suburbia study was restricted to creative industries workers who were able to support themselves primarily from their creative work and identified two distinct categories of CIW; "commercial creatives", - those people who either worked in, and/or ran a small to medium commercial enterprise (SME) - or 'artisans"' - those involved in generally individual creative endeavours such as visual art, music or writing" (Felton and Collis [18]).

The artisans of creative suburbia research relate closely to the characteristics of CIWs identified in substantive studies into a "vernacular creativity" (Edensor et al. [19]) which argued for a rethinking of the constitution of creativity, and advocated the need to consider the often marginal and everyday spaces in which creative industry work takes place. Both the creative suburbia and vernacular creativity research strongly suggests that there is a suburban spread (of creative industries work and workers) and not the stupid suburban sprawl so criticised by the new urbanists (Duany et al. [16]).

The creative suburbia research involved over 170 interviews of suburbanbased CIWs, stretching from Melbourne, Victoria to Redcliffe, Queensland. The creative suburb research checked in on the emergent outcomes of the creative suburbia research through 13 interview sessions with CIWs and property developers (e.g. designers and builders of the Soho) operating in south-east Queensland, including one household of CIWs in Toowoomba.

The interviews and a series of resultant design workshops suggested three possible building typologies (and topologies on the lot/site): "studio" (this includes a small, typically one room self-contained apartment, as well as a space for arts, crafts, etc. - could be anywhere on the lot); "shop" (e.g. a gallery, office or retail outlet, which is typically at the front of the lot and close to the street); and "workshop" (for noisy or dirty work e.g. music recording, metal sculpture, which might be typically at the rear of a lot and accessed via a rear lane say to make it easy for the roadie).

The spatial requirements addressed in all of the interviews and brought to a head at the design workshops determined that the minimum internal spatial area for these working spaces should be $3.6 \times 3.6 \mathrm{~m}^{2}$, with ceiling height preferably over $3.0 \mathrm{~m}$. These dimensions reflect a very clear consensus on some key design principles/requirements: CIWs want light and air, at least a courtyard outlook, a veranda, and if at all possible, a garden; and they also want to be able to walk or cycle around a neighbourhood and be close to parks, shops and other services. The latter are factors which flow through the creative city literature (Landry [4], Ebert and Kunzmann [20], Kim [21], Florida [2. 3]); whilst the former figure largely in the creative suburb literature (Collis and Felton [12], Felton [22]). 
The ability to have choice in spatial use, via flexible open spaces within the building or in a separate building within the lot, has become fundamental in considerations on building designs. Initially, it was considered that the adoption of "shop", "workshop" and "studio" would sufficiently express this flexibility in that buildings respectively available for "retail", "service/industry" and "commercial" use could be suitable and very attractive to other home-based business operators or hobbyists as they could be for CIWs. Eventually, however, the call to flexibility in response to the "flex" and "flux" of life and work for CI homeworkers determined that a broader categorisation of spaces and places be generated - to some extent an ambiguity of spatial use and definition is demanded - to open up consideration for the immense variety of creative industries work which could be undertaken. The following terms, thus, became a necessary lexicon, indeed a poetic pattern language (see Alexander [23]) in particular focusing the detailed interior and exterior design of a 'showcasestudy' 'homeworkhouse' for 88 East Street, Clifton in the Toowoomba region.

Residential space - a living and/or dwelling space "recreational" homework

Exhibition space - a display space for installations, artworks (e.g. gallery), projections and/or functions as well as a place where wares/goods are offered for retail/sale to customers (shop/store)

"retail" homework

Performance space - a space for presentations, concerts, recitals, and shows including music, aerial circus, lectures, and workshops in the sense of a space for a group of people working on a creative project, discussing a topic, or studying a subject - includes space for an audience as in a theatre (which may also overlap with showing of a movie or other projection as part of an exhibition)

"expressive" homework

Storage space - a space to store, stock and/or hold something for safekeeping including a "warehouse", as against a "store" where stuff is stored/kept for sale "contained" homework

Workshop space - a space where wo/manual work is done, especially manufacturing or repairing and/or sculpting - can include a "garage" in the sense of motorcycle maintenance or simply storing a precious motor vehicle or two (note overlap with storage space)

"service-industrial" homework

Writer's space - a space where any type of written work is done, including an office, study, library, or retreat - typically a space or room, a curio or bureau which can include for the creative writer a plethora of "ritualistic paraphernalia", but at the very least; "a chair, a table, silence, and a little awe" (Maisel [24])

"commercial" homework 
It was further determined that the preferred location and likely expression of each of the above uses and spaces led naturally to the coupling of residential + writer's, workshop + storage, and performance + exhibition spaces, which in turn meant that each building design in the creative suburb series would need to include at least one each of these combinations.

To ensure that one design had every chance of being built, the concept for the 'showcasestudy' 'homeworkhouse' at 88 East Street Clifton (Figure 5) thus involved the integration of the research findings, housing development industry best practice and planning scheme requirements:

- Compliance with the Toowoomba Regional Planning Scheme provisions for development in the Major Centre zone in the regional towns (this includes a requirement for the building to be constructed to the front boundary, and to have ceiling heights within the main part of the building of at least $3.0 \mathrm{~m}$ ) ironically the front building setbacks available in special 'master planned' or 'priority development' areas are not yet mainstream in Residential zone codes but are available in Centre zone codes in the Toowoomba planning scheme

- Consideration for "neighbourhood character" and heritage streetscape - e.g. the impression of a Queensland colonial cottage with a high ceiling and surrounding verandas

- Incorporation of an "industrial/commercial" feel in the building expression, including the pop-up roof and surrounding clerestory windows as a feature of what could be the "premium" range of designs (e.g. the main idea of this bank of windows is to enable high light and ventilation throughout all rooms in the design)

- The building is 'front-loaded' from the street - no rear lane access (although rear lanes are important in the urban design where flexibility is a design driver)

- An on-site car parking space for each of the possible 'tenancies' is provided, in particular for sub-lessees and/or visitor/customer parking for non-resident CIWs - whilst the idea of a suburb of 'homeworkhouses' for CIWs is premised on reducing or removing the home-work commute, public transport is virtually non-existent in the Toowoomba region and the scheme requires off-street parking for employees of home-based businesses in any case

- The design includes an exhibition/performance space, a writer's/residential space, a storage/workshop space, and an all-residential space, each of which could be adapted for the full gamut of creative industries work or for allresidential purposes (intergenerational homework and residential design)

These parameters were then used to generate 45 concept building designs on 'lots' (site for a single 'homeworkhouse') with industry standard depths of 18, 25 and 32 metres (ULDA [25]). The building modules determined the typical lot widths of 6.3, 9.0 and 11.7 metres with some minor variations to suit typical 'block' dimensions of 57 by 130 metres (ULDA [25]), a 'block' being a collection of lots surrounded by streets. The requisite combination of blocks comprising lots with immediate street access ('front-loaded' lots) and access via rear lanes ('rear-loaded' lots) generated a concept design for a new 'knowledge neighbourhood' based entirely on building designs for 'homeworkhouses' suited to CIWs (Figure 6). 

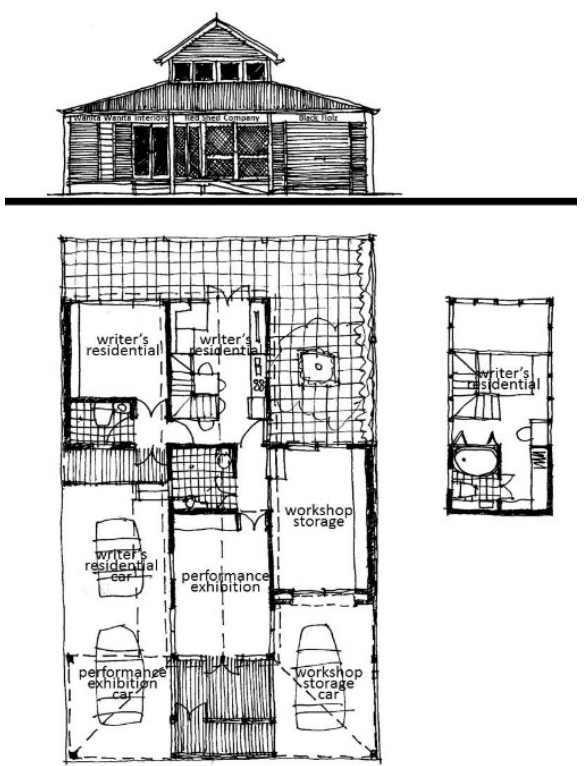

Figure 5: Concept design for 'showcasestudy' 'homeworkhouse' at 88 East Street, Clifton, Toowoomba region, Queensland.

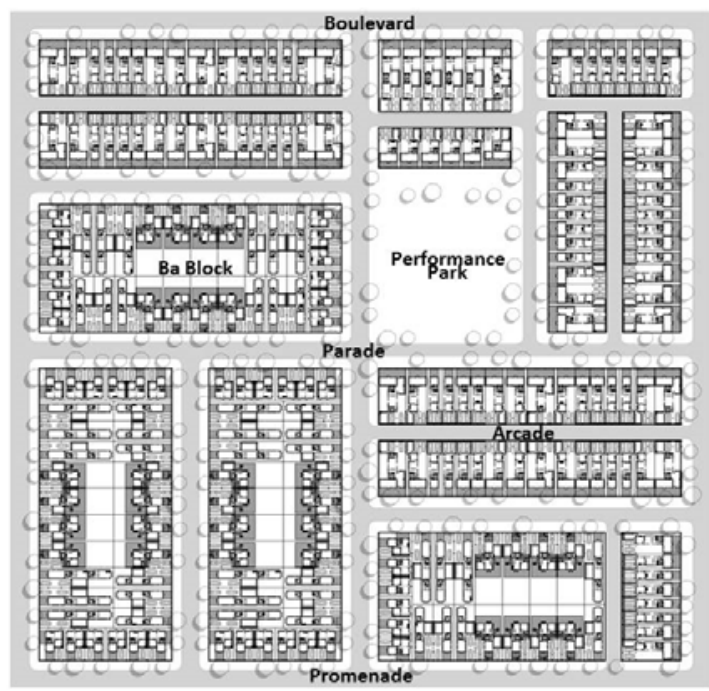

The knowledge neighbourhood

Homeworkhouse footprint, ba blocks surrounded by sage streets, including a non-vehicular access boulevard (top and right of

knowledge neighbourhood edge) and a parade (bottom and left) with immediate "front-loaded" street access. Derformance park is off

centre but within a 260 metre walk of every homeworkhouse in the knowledge neighbourhood.

Figure 6: A "knowledge neighbourhood" - a key component of The Creative Suburb. 


\section{Conclusion}

The creative suburb building designs draw substantially on the adoption of a vernacular approach, which has the potential for application and inspiration beyond Queensland and Australia. Indeed, the practice-led and industry-embedded vernacular nature of the outputs of this research has the potential to avoid the criticisms typically - and quite rightly - aimed at architects who take a moral highculture ground in the battle against suburban sprawl. Early indications are that the 'homeworkhouse' designs could easily compete with and be a more attractive, robust and flexible proposition than mainstream, domestic and traditional suburban housing designs. In some respects the designs also reflect a burgeoning micro-property movement, which nonetheless respect those of us with mobility and other physical challenges, who should find it easy to manoeuvre in what are small houses by current Australian trends. If these factors prove to be the case, then support for new greenfield suburban development of the density and diversity envisaged in the Creative Suburb will continue, the resultant reduction of the commute the most significant contributor to the sustainability of our growing cities; the next phase of this research to therefore consider the potential for the Creative Suburb principles and outcomes to apply to existing suburbs.

\section{References}

[1] Florida, R. The Rise of The Creative Class: And How It's Transforming Work, Leisure, Community and Everyday Life. Basic Books: New York. 2002.

[2] Florida, R. Who's your city? Basic Books: New York. 2009.

[3] Florida, R. The Rise of the Creative Class Revisited. Basic Books: New York. 2012.

[4] Landry, C. The Creative City: A tool kit for urban innovators. Earthscan Publications Ltd: UK. 2008.

[5] Evans, G.L. From cultural quarters to creative clusters - creative spaces in the new city economy, 2009.

http://www.citiesinstitute.org/londonmet/fms/MRSite/Research/cities/079cultural quarters and urban_regeneration-090722-evans.pdf

[6] Higgs, P., Cunningham, S., Pagan, J. Australia's Creative Economy: Definitions of the Segments and Sectors, ARC Centre of Excellence for Creative Industries \& Innovation (CCI), Brisbane. 2007. http://eprints.qut.edu.au/archive/0008242/>

[7] Collis, C., Felton, E. \& Graham, P.W. Beyond the inner city: real and imagined places in creative place policy and practice. The Information Society, 26(2). 2010.

[8] Gibson, C., Luckman, S. \& Willoughby-Smith, J. Creativity without borders? Rethinking remoteness and proximity. Australian Geographer, 41 (1), 25-38. 2010. 
[9] Flew, T. Creative suburbia: Rethinking urban cultural policy - the Australian case International Journal of Cultural Studies 2012 15: 231. 2012.

[10] TRC. Toowoomba Regional Council Planning Scheme, 2012. http://toowoombarc.qld.gov.au

[11] SPA. Sustainable Planning Act 2009. https:/www.legislation.qld.gov.au/LEGISLTN/CURRENT/S/SustPlanA0 9.pdf

[12] Collis, C. \& Felton, E. Creativity and the Australian suburbs: the appeal of suburban localities for the creative industries workforce. Journal of Australian Studies 36:2, 177-190. 2012.

[13] Heidegger. M. Poetry Language Thought. New Harper and Row: New York 145-146. 1975.

[14] Williams, P., Pocock, B. \& Bridge, K. Linked Up Lives: Putting Together Work, Home and Community in Ten Australian Suburbs. np.: Centre for Work + Life, University of South Australia. 2009.

[15] Katz, P. The New Urbanism: Toward an Architecture of Community. McGraw Hill: New York. 1996.

[16] Duany, A., Speck, J., Lydon, M. The Smart Growth Manual. McGraw Hill: np. 2010.

[17] Felton, E. \& Collis, C. Creativity and the Australian suburbs: the appeal of suburban localities for the creative industries workforce. Journal of Australian Studies. 2012.

[18] Felton, E. \& Collis, C. Creativity and the Australian suburbs: the appeal of suburban localities for the creative industries workforce. Journal of Australian Studies. pp. 180-181. 2012.

[19] Edensor, T., Leslie, D., Millington, S., Rantisi, N.M. (Eds.). Spaces of Vernacular Creativity: Rethinking the Cultural Economy. Routledge: Abingdon, Oxon. 2009.

[20] Ebert and Kunzmann. Creative Cities, Creative Spaces, Creative Urban Policies, Toward a Creative City: International Experiences Conference Proceedings, Korea (pp. 37-56). np.: Daejeon Metropolitan City World Technopolis Association: np. pp. 37-56. 2008.

[21] Kim, J. Towards Creative City: Perspectives from the Phoenix Metropolitan. In Toward a Creative City: International Experiences Conference Proceedings, Korea. Daejeon Metropolitan City World Technopolis Association: np. pp. 37-56. 2008.

[22] Felton, E. Working in the Australian suburbs: Creative industries workers' adaptation of traditional work spaces. City Culture and Society. 2013.

[23] Alexander, C. The Timeless Way of Building. Oxford University Press: New York. 1979.

[24] Maisel, E. The Writer's Space: Adams Media: Massachusetts. p. 5. 2008

[25] ULDA. ULDA guideline No. 1 Residential 30. Queensland Urban Land Development Authority. 2010. 